\title{
ANALISIS UNSUR SEMIOTIKA PENGGUNAAN BAMBU PADA MASYARAKAT ETNIK MANDAR
}

\author{
Abdul Asis ${ }^{*}$, Muhammad Firman Halip ${ }^{1}$ \\ IUniversitas Al AsyariahMandar \\ *Email: abdulasis1989@gmail.com
}

\begin{abstract}
The Mandar tribe is one of the tribes in the province of West Sulawesi which has various local wisdoms. The Sendana community as one of the communities in the land of Mandar calls the name bamboo Tarring, in Sendana Village there are many types of bamboo that are grown and deliberately planted by residents, with many types of bamboo there are some of the residents who do not know the name, type, and use as well as the special meaning in the bamboos they encounter. This research is expected to provide useful data information in supporting the science of bamboo plants, as well as a library material for related parties in the context of developing the potential and utilization of bamboo. This research is a qualitative research with an interpretive description approach. Furthermore, the research refers to a semiotic analysis study based on Ferdinand De Saussure's theory by looking at the markers (signified) and markers (signifier) contained in the arrangement of the use of bamboo. Data collection techniques will use a documentation and interview system. Based on the results of the semiotic analysis of the use of bamboo in every activity that is considered sacred and the use of bamboo as the main material for the holy prayer, including substances that form the body, human existence, worship, forming blood according to its function, the cycle of human life, the structure of the building (Gazebo), tourism Mandar.
\end{abstract}

Keywords : semiotic analysis, bamboo, tourism

\section{PENDAHULUAN}

Tumbuh-tumbuhan tidak dapat lepas dari kehidupan manusia apalagi masyarakat pedesaan, salah satu jenis tumbuhan yang paling banyak digunakan oleh masyarakat adalah bambu (Hartanto, L, 2011; Widjaja, E. A. 2016; Hingmadi, D. 2012; Linda, dkk. 2012; Mayasari, A. \& Suryawan, A. 2012; Prasetiyo, S. 2009) kegunaan dan manfaat bambu bervariasi mulai dari perabotan 
rumah, perabotan dapur dan kerajinan, bahan bangunan serta peralatan lainnya dari yang sederhana sampai dengan industri bambu lapis, laminasi bambu, maupun industri kertas yang sudah modern. Sendana adalah salah satu nama desa dari Kecamatan Sendana yang terletak di Kabupaten Majene, masyarakat setempat merupakan masyarakat asli suku Mandar yang tinggal Majene, berdasarkan pengamatan observasi peneliti pada April 2017, maret 2018 dan pada awal agustus 2019 masyarakat Sendana menyebut nama bambu dengan sebutan Tarring, di Desa Sendana ada banyak jenis bambu yang tumbuh dan sengaja ditanam oleh warga, dengan banyaknya jenis bambu ada sebagian dari warga yang tidak mengetahui nama, jenis, dan kegunaan serta makna khusus pada bambu yang mereka temui. Penelitian ini diharapkan dapat memberikan informasi serta data yang bermanfaat dalam menunjang ilmu pengetahuan mengenai tanaman bambu, serta menjadi bahan kepustakaan bagi pihak-pihak terkait dalam rangka pengembangan potensi serta pemanfaatan bamboo.

Dalam hal mendukung program pemerintah setempat dalam upaya pewarisan berbagai kearifan lokal masyarakat mandar serta untuk mengangkat dan memperkenalkan berbagai kebudayaan yang ada suku mandar agar tidak tergerus oleh berbagai pengaruh budaya asing serta mampu tetap eksis dalam persaingan global maka inilah yang menjadi dasar peneliti mengangkat topik kajian simiotik pada penggunaan bambu. Selain itu, Salah satu kendala dalam mewariskan budaya lokal yang bernilai ini adalah masih minimnya Bahan referensi sehingga hal ini dapat memicu para generasi sukar mendapatakan berbagai pengetahuan tentang kebudayaan lokal. Hasil penelitian ini akan dikemas menadi sebuah buku bacaan yang kemudian diharapkan bisa dijadikan sebagai bahan referensi dalam memepelajari berbagai system kebudayaan suku Mandar.

\section{METODE PENELITIAN}

Identifikasi bambu dilakukan dengan menggunakan analisis Semiotik, yaitu identifikasi yang dilakukan dengan cara mengetahui karakteristik Bambu dengan literatur yang terdapat dalam kunci determinasi baik segi bentuk, fungsi serta makna literatur penunjang lainnya. Tempat penelitian tersebut dilaksanakan di Sendana pada tahun 2019-2020. Peneliti selanjutnya menggunakan pendekatan deskriptif-interpretatif yang berupa pemberiaan gambaran sedetail mungkin agar bisa memberikan informasi yang mendalam terkait pemahaman terhadap tandatanda (Sign).

Teknik pengumpulan data pada penelitian menggunakan Data kualitatif yang bersifat objektif. Dokumentasi serta wawancara yang akan digunakan, dimana Pengumpulan data dilakukan dengan mengambil gambar berbagai objek kemudian mencetak foto-foto yang telah didapatkan, kemudian peneliti 
melakukan analisisyang merujuk pada kandungan pesan dan makna dari sebuah gambar dan mencatat. Selain itu, peneliti juga melakukan proses wawancara. pertanyaan yang diajukan tidak berstruktur, dan dalam suasana bebas. Peneliti mencoba menghilangkan kesan formal, walaupun tetap saja tidak dapat menghilangkan kesan sebagai -orang asing bagi informan. Penelitian dilakukan selama 1 tahun setelah pengumpulan data hingga kesimpulan, melalui beberapa tahapan yaitu: Memilih masalah, melakukan studi pendahuluan atau studi eksploratoris, Perumusan masalah, Mengumpulkan data, Analisis data,hinggap pada tahap Kesimpulan.

Penelitian ini menggunakan analisis semiotika Ferdinnand De Saussure ,dimana focus utamanya ada pada tanda itu sendiri. Peneliti akan mencari penanda (signifier),dan petanda (signified) kemudian mengkaji pesan dan makna dibalik tanda tersebutdan dijelaskan kedalam table 1 sebagai berikut :

Tabel 1. Analisis Makna

Sumber: Hasil Olah Data 2020

\begin{tabular}{|c|c|}
\hline Tanda \\
\hline Penanda & Petanda \\
\hline Citra Bentuk & Konsep \\
\hline
\end{tabular}

Sebagaimana sajian table tersebut, Tahapan penelitian yang akan dilakukan berdasarkan teori semiotika Ferdinand De Saussure adalah sebagai berikut:

1. Penanda (signifier): mencari tanda berdasarkan letak, bentuk, ukuran, dan warna yang terdapat pada penggunaan bambu: Identitas, Budaya, dan Fashionll.

2. Petanda (signified): mendefenisikan penanda (signifier) kedalam sebuah konsep.

3. Makna : mengkombinasikan antara penanda (signifier) dan petanda (signified), kemudian mengungkapkan sebuah makna dalam penggunaan bambu.

4. Pesan : tahap terakhir yaitu mengungkap pesan yang ingin disampaikan oleh Masyarakat suku mandar yang menjadi objek penelitian. 


\section{HASIL DAN PEMBAHASAN}

Ilustrasi yang disajikan pada penggunaan bambu dari berbagai aspek kemanfaatan baik dari segi makna, jenis dan fungsinya terdapat beragam symbol, Walasuci/Balasuci, garis melintang pada lantai atau dinding Bambu, Ayaman bamboo, tataletak. Makna yang terkadung dalam setiap penggunaan bamboo secara detail akan diuraian berdasarakan sejumlah hasil pengumpulan data baik melalui wawancara maupun dokumentasi.

\section{Walasuci}

Walasuci secara umum tidak hanya dikenal disuku mandar tetap juga dikenal luas wilayah Sulawesi bagian selatan. Walasuci juga sering disebut Balasuci, Bala Suji/lawa, Walasoji. Menurut Hassami (45) adanya sejumlah versi penyebutan dari Walasuci ini dipengaruhi oleh setiap perbedaan Bahasa daerah serta kondisi geografis setiap wilayah. Lebih lanjut menurutnya memang secara umum terdapat ratusan bahkan diperkirakan seribuan lebih kata bahkan frase yang memiliki arti dan defenisi yang sama namun perbedaan hanya terdapat pada fonemnya saja. Misalnya suku mandar menyebutnya Walasuci sementara suku bugis menyebut Balasuci. Bala Suji/Lawa Soji/Walasoji, ini merupakan sebutan nama dari anyaman bambu khas suku mandar khususnya diwilayah sendana Sulawesi barat. Anyaman yang dibuat dengan berbahan dasar bambu teridiri dari sejumlah bilah bambu dan sengaja dibuat untuk berbagai bentuk sesuai tujuan pembuatannya, contohnya sebagai wadah untuk mengantar sejumlah seserahan dari calon mempelai pria kepada calon mempelai wanita yang diisi dengan berbagai macam buah-buahan, juga di fungsikan sebagai pembatas pelaminan antara mempelai dengan undangan, dan atau sebagai ornamen pada pintu gerbang dalam ritual adat perkawinan.
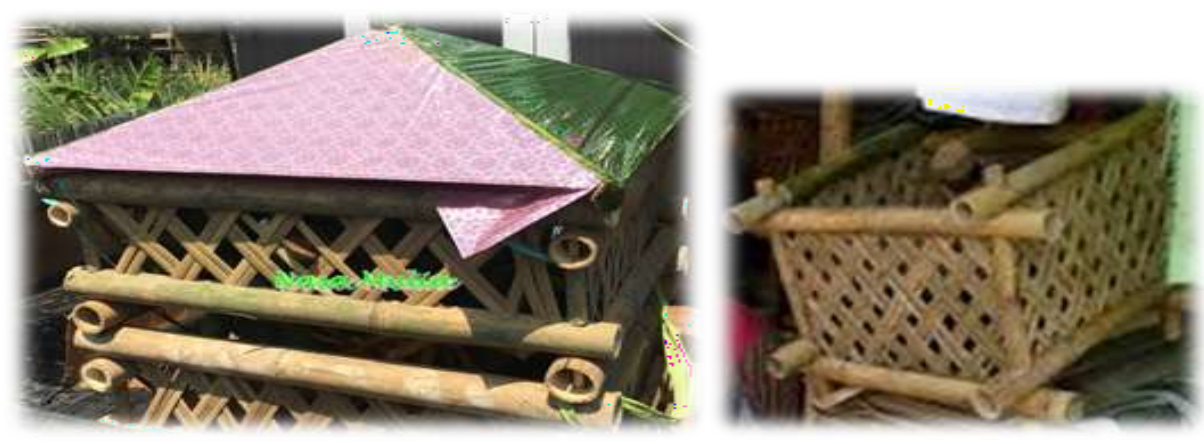

Gambar 1 Bala suci/ wala suji Balasuci juga kerap kali digunakan untuk meletakkan orang meninggal sebelum dibawa kepekuburan, sering pula bala suji digunakan ketika melakasanakan ritual kelahiran bayi dimana bala suji di tempatkan dibawah kolom rumah yang sejajar dengan tempat sang ibu. Suku 
bugis menamainya lawa soji atau bala suji dalam bahasa mandar. Walaupun memiliki penyebutan yang berbeda namun mempunyai defenisi dan pengertian yang sama yaitu Lawa yang berarti pembatas dan suji yang berasal dari Lontara I Lagaligo yang berarti agung atau suci.

Dengan demikian bisa dikatakan bahwa lawa suji merupakan pembatan atau sebuah pagar berfungsi untuk memagari sesuatu yang sifatnya bersih, suci atau agung. Setiap pembuatan lawa suji/bala suji, bilah bilah bambu yang telah dipotong rapi selanjutnya dilakukan anyaman secara diagonal dengan jarak tertentu sampai Nampak terbentuk menyerupai belah ketupat. Menurut Wahyu bentuk lawa suji ini tidak bisa dilepaskan dari kepercayaan mikrocosmos masyarakat sulawesi selatan dan barat tentang sulapa eppa/sulapa appe yang memuat ajaran sosiokultural dan spritual. Lebihlajut wahyu menambahkan Balasuji seganja dibuat dari bambu yang tidak terlalu tipis kemudian dianyam secara diagonal dengan ukuran jarak tertentu sampai Nampak lubang simetris diantara anyamannya yang menyerupai belah ketupat. Menurut penuturannya, bahwa dahulu di kalangan kerajaan jumlah bilah bambu pada anyaman bala suji menunjukkan derajat sosial dari yang punya hajatan.

Untuk kalangan bangsawan memakai tiga bilah bambu yang dianyam dan menempatkan bilah yang memiliki kulit diapit bilah bambu yang kulitnya telah dibuang dikedua sisi bilah bambu berkulit tadi sehingga Nampak warna khas krem, hijau,krem jika menggunakan bambu hijau atau krem, kuning, krem saat menggunakan bambu tua/bambu kuning. hal Ini mengilustrasikan tentang seorang raja yang memiliki penampilan lebih perkasa, menarik, kuat, bersifat melindungi (kulit bambu lebih kuat dan melindungi bagian dalam bambu) berada di tengah dan diapit oleh rakyat atau pengawalnya. Sementara untuk orang biasa menggunakan anyaman dua, dengan cara dua bilah bambu yang salah satunya berkulit dan yang satunya tidak di anyam sejajar sama dengan anyaman yang menggunakan tiga bilah bambu. hal ini menunjukkan bahwa pemilik hajatan bukan merupakan pemimpin dan tidak punya pengawal, sementara untuk kalangan budak tidak menggunakan lawa suji. Menurut Kahar (35) sangat disayangkan terdapat banyak masyarkat suku mandar yang kurang memahami makna yang terkadung dalam setiap pembuatan balasuci ketika melaksanakan sebuah hajatan baik berupa nikahan, maulid, syukuran, dll. Sehingga tidak sedikit meleset dari makna yang sesungghunya sehingga tidak mampu merepresentasikan derajat sosial yang sebenarnya.

\section{a. Makna}

Berdasarkan wawancara mendalam terhadap beberapa informan bahawa, lawa suji memiliki banyak versi tentang makna yang tersirat dalam bentuk anyamannya yang menyerupai ketupat, antara lain: 
1. Zat pembentuk tubuh

Masyarakat suku mandar meyakini terdapat empat unsur pembentuk tubuh sebagaimana digambarkan empat sudut bala suci yaitu:- Api, Angin, Air, dan Tanah.

2. Eksistensi manusia

Suku mandar juga menganggap bahawa bala suci menggambarkan akan keberadaan manusi dalam dunia dan bagiaman manusia memahami terhadap hakikat penciptaan dirinya, bagaiaman manusia memahami hubungannya dengan Tuhannya, wujud manusia memahami hubungan dengan alam serta bagaimana manusia memahami terhadap pemimpinnya.

3. Ibadah

Selain makna eksistensi manusia, masyarakat suku mandar juga menganggap bahwa walasuci juga sebagai bentuk symbol dari tugas utama manusia yaitu beribadah yang termanifestasi dari empat sudut walasuci yaitu - Berdiri, - Rukuk, - Sujud, dan - Iqtidal. Menurut habri bahwa keempat symbol ini mengilustrasikan roda kehidupan manusia. Lebih lanjut ia menambahkan bahwa Simbol berdiri menunjukkan bahwa derajat sosial manuasi kadang berada diposisi atas atau sebagai penguasa, bangsawan. Namun kadang kala turun pada posisi menengah yang tergambarkan pada posisi Rukuk, bahkan kadang juga manusia berda diposisi paling bawah yang termanisfestasi kedalam sujud.

4. Pembentuk darah sesuai dengan fungsinya

Dipercaya pula oleh kalangan suku mandar bahwa walasuci juga merupakan suatu simbolik darah manusia yang tergambarkan dari warna walasuci yang diberikan. Dimana terdapat empat kategori warna darah yang terkadung didalamnya yaitu - Darah merah sebagai lambing penggerak tubuh, - Darah hitam sebagai bentuk kekuatan tubuh manusia, - Darah putih sebagai wujud dari pertahanan dan - Darah kuning untuk memperbaiki/menyembuhkan tubuh pada saat luka.

5. Siklus kehidupan manusia

Selain itu makna lain yang tergambarkan dalam penggunaan walasuci/balasuci menurut masyarakat suku mandar menujukkan empat siklus kehidupan manusia yang dimulai sejak - Lahir, Syukuran/ritual/ibadah harian, - Perkawinan dan - Kematian.

Dari sejumlah makna yang berhasil diungkap oleh peneliti, kami meyakini masih ada sejumlah makna lain yang mungkin belum terungkap mengingat terdapa begitu banyak versi baik dari versi suku bugis, pattinjo, mandar dll. Hal ini sangat perlu dilakukan penelitian lebih lanjut sehingga banyak referensi untuk 
bisa menafsirkan makna yang terkandung didalamnya. Hal ini tentu tergantung dari masing-masing orang yang menafsirkannya.

Lalu pertanyaan besar, kenapa mesti menggunakan bambu dan bukan bahan lain misalnya rotan atau yang lain?.

beberapa philosofi tersendiri yang terkandung didalam penggunaan Bambu sebagai bahan pembuatan balasuji antara lain:

1. Bambu merupakan tumbuhan yang memiliki nilai guna yang banyak digunakan oleh masyarakat umum, ini bermakna bahwa semoga orang-orang yang memahami balasuji bisa menjadi orang yang berguna bagi masyarakat umum dilingkungannya.

2. Bambu merupana satu jenis tumbuhan yangmemiliki batang bulat, dan memiliki kulit bagian luar lebih keras daripada bagian dalamnya. Ini menggambarkan makna bahwa masing- masing dari keempat sisi pada balasuji harus saling menjaga dan bersatu dalam mufakat pada setiap kegiatan yang dilakukan.

3. Pohon bambu bersifat liat dan lentur, ini menunjukkan makna agar kita seharusnya menjadi orang yang ulet, gigih namun tetap dinamis dalam menghadapi dinamika hidup.

4. Tunas bambu muda atau sering disebut masyarkat lokal Habbuq dapat menjadi bahan makanan, ini bermakna bahwa setiap manusia hendaknya sejak masa kecilnya dapat membawa kebahagiaan dan keceriaan bagi keluarga dan lingkungannya serta bisa menjadi pelindung setelah ia beranjak dewasa.

Dari beberapa data tersebut merupakan olahan data berdasarkan hasil wawancara dan dokumentasi yang telah dilaksanakan sejak awal april hingga agustus 2020 selain itu juga mengkombinasikan dari beberapa data yang diperoleh dari hasil penuelusuran sejumlah kajian pustaka untuk memperkuat data yangtelah diperoleh dari lokasi penelitian.

\section{b. Struktur Bangunan Tempat (Gazebo) Wisata Mandar}

gaya rancangan suatu konstruksi bangunan tradisional oleh suatu suku bangsa yang berkembang merupakan salah satu aspek-aspek tradisi budaya bangsa Indonesia. Demikian halnyadengan suku mandar yang ada disulewesi barat. Sejumlah arsitiketur bagungan memiliki nilai simbolik tersendiri yang belumtentu dikenal oleh banyak masyarakat luas. Pengenalan serta pengetahuan tentang aspek-aspek tersebut termasuk nilai-nilai terkandung didalamnya memiliki makna penting untuk kehidupan yang harmonis dalam kehidupan sosial masyarakat yang terdiri atas berbagai unsur yang berbeda sifat atau beraneka ragam. 
Upaya inventarisasi arsitektur tradisional, adalah suatu bentuk kegiatan yang yang akan terus berlanjut. rancangan arsitektur tradisional menggambarkan kajian terhadapap suatu arsitektur dan tradisi, keduanya senantiasa bergerak dinamis. Umumnya orang berpendapat bahwa tradisi adalah segala sesuatu yang berulang sebagai model yang didapatkan pada masa lalu. Itu sebabnya kajian tradisi erat kaitannya dengan sejarah dan masa lampau.

Studi ini merupakan analisis yang berhubungan dengan sistem tanda dan lambing yang terdapat pada penggunaan bambu untukdijadikansebagai tempat wisata yang terdapat disuku mandar atau singkatnya merupakan analisi semiotik terhadap arsitektur tempat wisata yang semuanya berbahan dasar bamboo. Kerangka kajian ini diletakkan dalarn perspektif budaya, misalnya dengan melibatkan perspektif antropologi, arkeologi dan sejarah, itu sebabnya terdapat tiga hal utama yang menjadi perhatian utama. Pertama, perhatian dititikberatkan terhadap model, struktur bangunan yang menjadi obyek kajian. Dalam hal ini, bangunan yang akan ditilik adalah bangunan Gazobo yang hamper seratus persen terbuat dari bamboo.

Upaya pengumpulan data (tentang kebudayaan arsitektur tradisional Orang Mandar yang disajikan kali ini mempakan analisis semiotik yang terdapat pada penggunaan bamboo sebagi bahan utama tempat wisata. Makna terkadung didalamnya tidak terlepas dari makna simbolik yang terdapat pada boyang, baik boyang adaq maupun boyang beasa. Dengan kata lain Makna verbal yang terdapat pada penggunaan bamboo sebagai tempat wisata (gazobo) merupakan manifestasi dari makna simbolik arsitektur boyang.

Unsur semiotika yang terdapat dalam arsitektur tempat wisata diwilaya majene merupakan sebuah tanda dan mengandung bahasanya sendiri ini dan tersirat sejak arsitektur itu ada. perintisan ke arah Semiotika Arsitektur sebenarnya dimulai pada akhir tahun lima puluhan di Italia (Hartanto, L. 2011) sejak itu terjadi krisis makna di Eropa, dan muncul sejumlah perdebatan terhadap keabsahan Arsitektur Modern yang ingin memadukan semua nilai akibatnya seolah- olah tidak memberi kesempatan bagi pertumbuhan warna lokal. Pada tahap awal, para perintis mulai menganalogikan unsur-unsur pembentuk arsitektur dengan unsur-unsur pembentuk bahasa. Dengan sejumlah penyederhanaan, analogi itu dapat diuraikan sebagai berikut: unsur-unsur arsitektur (jendela, pintu, atap) dianalogikan dengan kata; dimana gabungan dari beberapa kata bisa membutuk sebuah kalimat yang dapat memberi informasi sempurna, maka gabungan unsur suatu arsitektur bangunan bisa memberi arti membentuk ruang. demikian seterusnya: ruang dianalogikan dengan sebuah kalimat, bangunan dengan paragraf, dan kompleks lingkungan binaan dengan sebuah wacana. Analogi ini membuka wawasan baru tentang sistem komunikasi sebuah karya arsitektur. Analogi ini dekat dengan konsep Roland Barthes 
tentang "Sistem dan Paradigma". Menurutnya, sebuah system merupakan aturan main terhadap suatu teks sehingga teks tersebut dapat melahirkan sebuah makna. Sistem ini sama dengan gramatika dalam bahasa atau dengan kata lain tatabahasa. Sedangkan paradigma merupakan macam unsuur-unsur pembentuk sistem tersebut. Dalam linguitik, paradigma berupa kosa kata. Suatu sistem dapat mempunyai makna bila terdapat kecocokan pada paradigma yang digunakan. Dengan pendekatan Barthes, maka bentuk tempat wisata yang yang terbuat dari bamboo mempunyai sistem atau gramatika sebagai sub struktur (fondasi), kolom, dinding pengisi, dan atap. Masing-masing mempunyai paradigma fondasi, fondasi tiang, dinding, dinding partisi, kolom, atap dan seterusnya. Sebuah rumah bisa disebut arsitektural atau indah secara arsitektur, bila paradigma-paradigma tersebut serasi satu sama lain (lihat diagram 1).

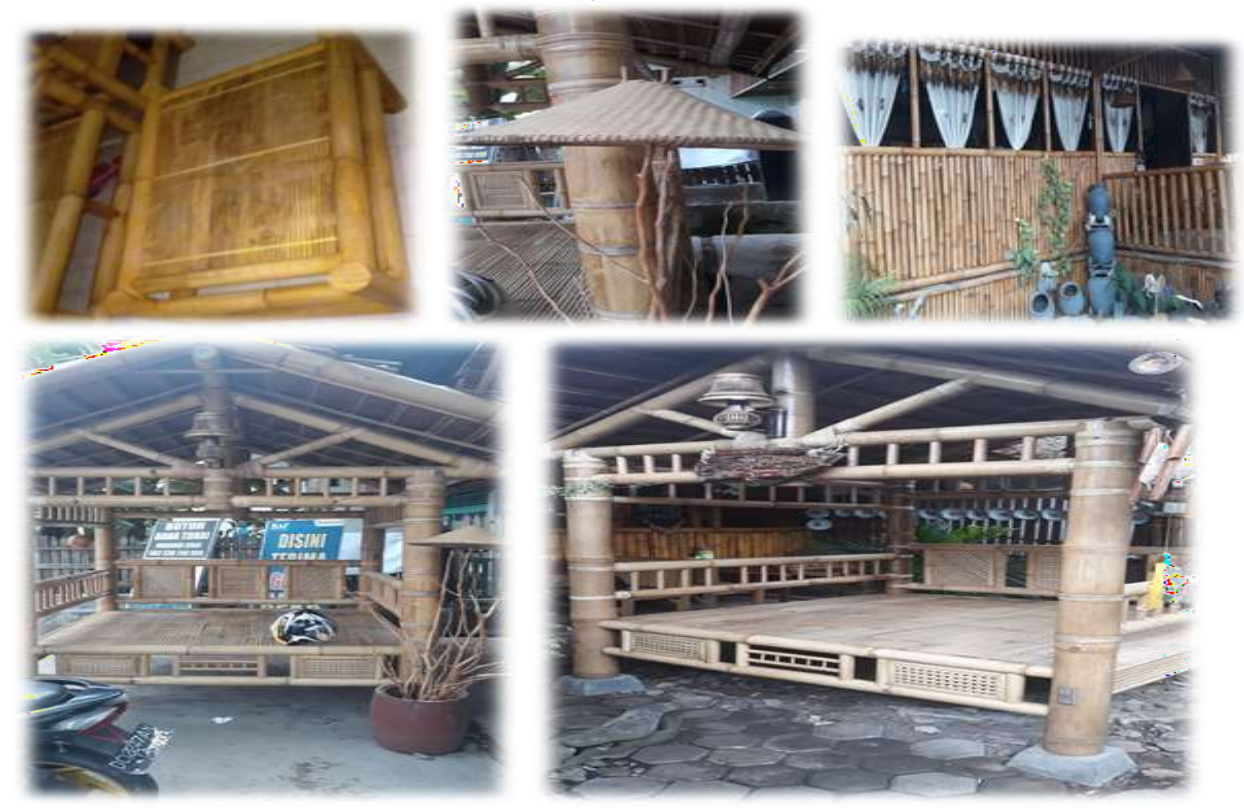




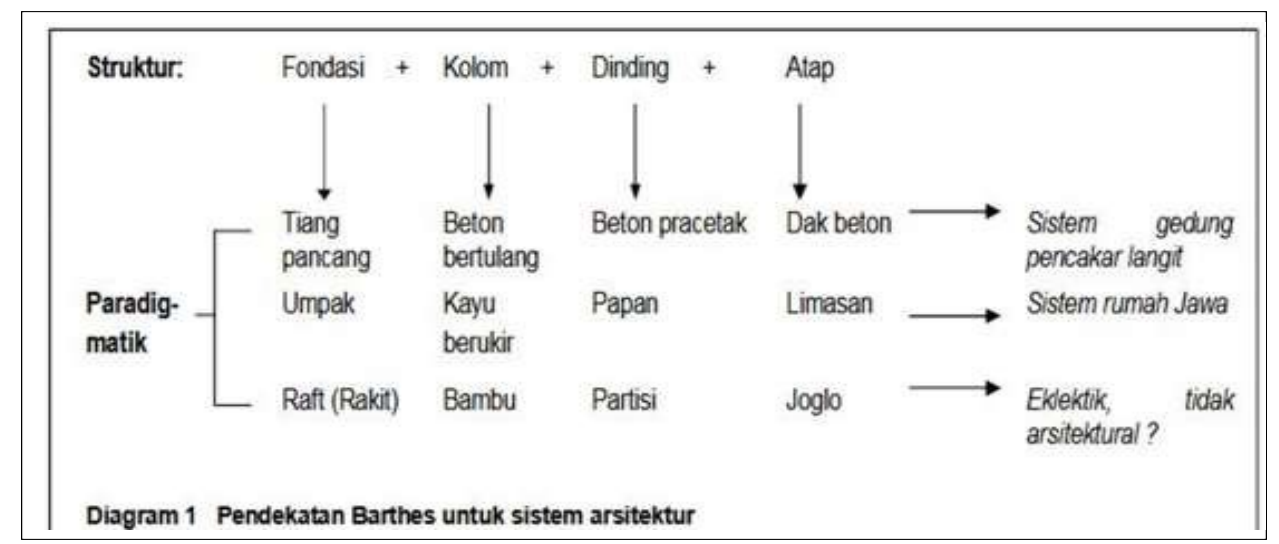

Seiring dengan perkembangan bidang ilmu semiotik kemudian muncul sejumlah model pendekatan dalam Semiotika arsitektur. Model yang cukup dikenal oleh banyak orang adalah pendekatan semiotik model Charles Sanders Pierce, dan model semiologi Ferdinand de Saussure. Pendekatan semiotik Pierce merupakan sebuah kajian tentang suatu pola perilaku manusia dalam komunikasi. Pendekatan pada arsitektur ini mengklasifikasi objek menjadi 3 jenis tanda: indeks, ikon, dan simbol. jika objek yang dikaji memiliki keterkaitan langsung antara penanda dengan makna disebut indeks, selanjutnya disebut ikon jika terdapat kesamaan antara penanda dengan yang direpresentasikan, dan disebut simbol jika hubungan antara penanda dan makna bersifat konvensional. Sementara Pendekatan semiologi Saussure mengkaji bagaimana sistem tanda bisa eksis di masyarakat. Pendekatan ini sering dinamakan pendekatan Semiotika strukturalis. Pendekatan ini memandang objek sebagai sebuah tanda (sign), yang mengandung unsur yang menandakan (signifier) dan unsur yang ditandakan (signified). Signifier dan Signified menyatu untuk melahirkan sebuah tanda atau sign, yang didasarkan pada referent yang telah dikenal. Sebagai contoh, peneliti mengangkat sebuah Gazobo yang hampir seratus persen berbahan material bamboo sebagai sebuah sign, mengandung signifier struktur bangunan dan signified tempat tinggal. Referent-nya adalah sesuatu yang berfungsi untuk melindungi serta sebagai tempat pencarian mata pencaharian manusia (lihat diagram 2) 


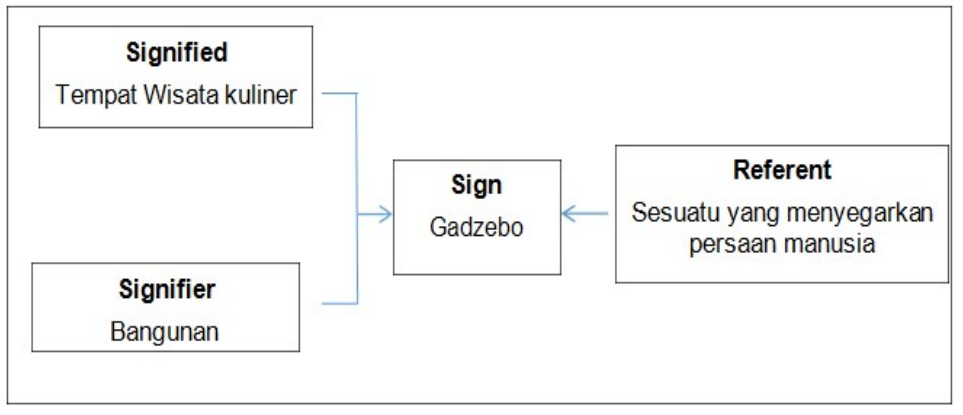

Diagram 2 Signifier dan Signified suatu gazebo

Pendekatan ini dianggap memiliki sistem tanda yang tidak dinamis, karena pada faktanya makna bisa mengalami pergeseran. Itu sebabnya model Semiotika ini dikembangkan dengan memberikan sebuah signified bisa menghasilkan signifier yang lain, yang berlanjut sehingga membentuk sistem tanda yang majemuk. Sebuah bangunan dapat mengandung signified tempat tinggal yang bagus. Tempat tinggal yang bagus bisa menghasilkan signifier bangunan mewah. tempat mewah membentuk signified kekayaan. Begitu seterusnya. (lihat diagram 3)

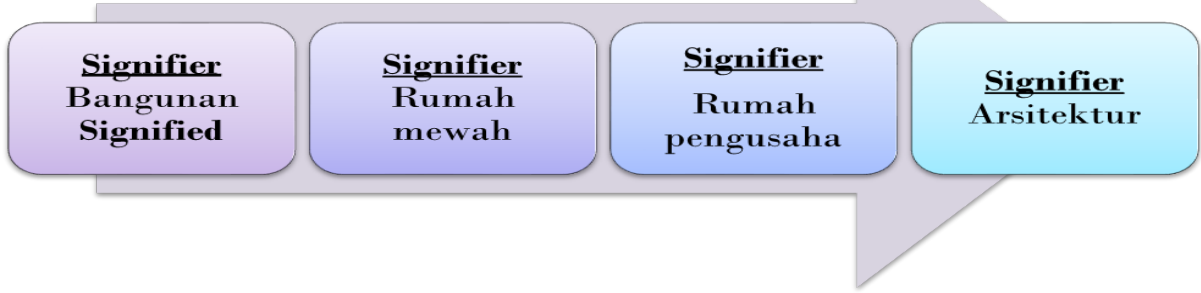

Diagram 3 Sistem tanda post struktur untuk rumah

\section{SIMPULAN}

Berdasarkan temuan dari analisis semiotik terhadap pemanfaatan bambu dalam setiap kegiatan yang dianggap sakral serta penggunaan bambu sebagai bahan material utama di tempat wisata majene, peneliti menarik kesimpulan bahawa masyarakat suku mandar dalam tradisinya tidak hanya sekedar memanfaatkan bambu sebagai salah satu bahan kebutuhan melainkan juga memanfatkan dengan membawa makna tersirat pada setiap penggunaannya. Sejumlah benang merah yang bisa peneliti tarik sebagai berikut: 
Analisi lawa suji/bala suci yang merupakan salah satu wadah tempat bingkisan pemberian memiliki banyak versi tentang makna yang tersirat dalam bentuk anyamannya yang menyerupai ketupat, antara lain: Zat pembentuk tubuh, Eksistensi manusia, Ibadah, Pembentuk darah sesuai dengan fungsinya, Siklus kehidupan manusia, Struktur Bangunan Tempat (Gazebo) Wisata Mandar yang mengklasifikasi objek menjadi 3 jenis tanda: indeks, ikon, dan simbol. jika objek yang dikaji memiliki keterkaitan langsung antara penanda dengan makna disebut indeks, selanjutnya disebut ikon jika terdapat kesamaan antara penanda dengan yang direpresentasikan, dan disebut simbol jika hubungan antara penanda dan makna bersifat konvensional. Sementara Pendekatan semiologi Saussure mengkaji bagaimana sistem tanda bisa eksis di masyarakat. Signifier dan Signified menyatu untuk melahirkan sebuah tanda atau sign, yang didasarkan pada referent yang telah dikenal.

\section{SARAN DAN REKOMENDASI}

Berdasarkan temuan sekaligus pembahasan di atas, maka peneliti memberikan saran bahwa dari sejumlah makna yang berhasil diungkap oleh peneliti, kami meyakini masih ada sejumlah makna lain yang mungkin belum terungkap mengingat terdapa begitu banyak versi baik dari versi suku bugis, pattinjo, mandar dll. Hal ini sangat perlu dilakukan penelitian lebih lanjut sehingga banyak referensi untuk bisa menafsirkan makna yang terkandung didalamnya. Hal ini tentu tergantung dari masing-masing orang yang menafsirkannya. Lalu pertanyaan besar, kenapa mesti menggunakan bambu dan bukan bahan lain misalnya rotan atau yang lain.

\section{DAFTAR PUSTAKA}

Hartanto, L. 2011. Seri Buku Informasi dan Potensi Pengelolaan Bambu Taman Nasional Alas Purwo. Banyu Wangi: TNAP (Taman Nasional Alas Purwo) Press.

Hingmadi, D. 2012. Laporan Penelitian PKL. Keanekaragaman Ciri Morfologi Jenisjenis Bambu di Kelurahan Teunbaun Kecamatan Amasari Barat Kabupaten Kupang. Laporan Penelitian PKL. Nusa Tenggara Timur: Fakultas Mipa-Biologi Universitas PGRI-NTT

KBBI, 2016. Badan Pengembangan dan Pembinaan Bahasa

Kopertis. Peraturan Pemerintah Republik Indonesia Nomor 19 Tahun 2005 Tentang

Standar Nasional Pendidikan.

https://kemenag.go.id/file/dokumen/PP1905.pdf

Kurniawati, Nia, Et.all. 2018. The praxis of digital literacy in the EFL Classroom: Digital immigrant vs Digital Native Speaker. Indonesian Journal of Applied 
Linguistics Vol. 8 No. 1

Linda, dkk. 2012. Inventaris Jenis Bambu di Hutan Gunung Semahung Dusun Petai Desa Saham Kecamatan Sengah Temila Kabupaten Landak. Jurnal Biologi, ISBN 20 (8), 333-338.

Lucky Zamzami, 2016. Dinamika Pranata Sosial Terhadap Kearifan Lokal Masyarakat Nelayan. Dalam Melestarikan Wisata Bahari. JURNAL ANTROPOLOGI: Isu-Isu Sosial Budaya. Juni 2016 Vol. 18 (1): 57-67 ISSN 1410-8356

Mayasari, A. \& Suryawan, A. 2012. Keragaman Jenis Bambu dan Pemanfaatannya di Taman Nasional Alas Purwo. Manado: Balai Penelitian Kehutanan Manado.

Prasetiyo, S. 2009. Identifikasi Potensi dan Pemasaran Produk Dari Hutan Rakyat Bambu. (Studi Kasus: Desa Pertumbukan Kec. Wampu Kab. Langkat). Skripsi. Medan: Fakultas Pertanian Universitas Sumatera Utara.

Rulliaty, dkk. 2015. Seri Paket Iptek Informasi Sifat Dasar dan Kemungkinan Penggunaan 10 Jenis Bambu. Bogor: IPB Prees Bogor.

Widjaja, E. A. 2016. Identifikasi Jenis-jenis Bambu di Kepulauan Sunda Kecil. Buku. Puslitbang Biologi-LIPI. Bogor. $57 \mathrm{hlm}$.

Winarto, V. dan D. Ediningtyas. 2012. Mau Tahu Tentang Bambu ?. Buku. Kementerian Kehutanan. Jakarta. 31 hlm. 